\title{
Integration of Dental Health Professionals in Disaster Management - Commitment to Action - New Delhi Declaration - 2020
}

\author{
Vikrant R. Mohanty; ${ }^{1}$ Rajesh G. Rao; ${ }^{2}$ Anil K. Gupta; ${ }^{3}$ Vamsi K. Reddy; ${ }^{4}$ Kavita Rijhwani; ${ }^{5}$ (i) \\ Fatima Amin 6
}

1. Professor and Head, Department of Public Health Dentistry, Maulana Azad Institute of Dental Sciences, Delhi, India

2. Former Professor and Head, Department of Public Health Dentistry, Manipal College of Dental Sciences, Mangalore, India

3. Professor, National Institute of Disaster Management, Government of India, India

4. Principal, Professor and Head, Department of Public Health Dentistry, Anil Neerukonda Institute of Dental Sciences, Visakhapatnam, Andhra Pradesh, India

5. Senior Resident, Department of Public Health Dentistry, Maulana Azad Institute of Dental Sciences, Delhi, India

6. Young Researcher, National Institute of Disaster Management, Government of India, India

Correspondence:

Dr. Vikrant Mohanty

Professor and Head

Department of Public Health Dentistry

Maulana Azad Institute of Dental Sciences

5th Floor MAIDS, MAMC Campus,

New Delhi, Pin -110002

E-mail: vikrantmohanty@gmail.com

Conflicts of interest/funding: none

Keywords: dentist; dentistry; disasters; public health; risk management

Abbreviations:

IAPHD: Indian Association of Public Health

Dentistry

NIDM: National Institute of Disaster

Management

SOP: Standard Operating Procedure

Received: October 15, 2021

Accepted: November 2, 2021
Mohanty VR, Rao RG, Gupta AK, Reddy VK, Rijhwani K, Amin F. Integration of dental health professionals in disaster management - commitment to action - New Delhi declaration - 2020. Prehosp Disaster Med. 2022;37(2):290-291.

Disasters have not only increased in frequency but also have changed in their patterns. The changes have been dynamic in nature and impacts have been manifold affecting millions of lives all over the world. ${ }^{1}$ Any disaster will firstly lead to fatalities and an upsurge in the number of individuals who need instant management by health care professionals. The response to disasters depends upon every country's public health system preparedness. Further, the backbone of any such response remains the health workforce. ${ }^{2,3}$ Hence inclusion of health care workers other than the traditional medical workforce in disaster management is the need of the hour. ${ }^{4}$ Dental health professionals constitute one such source of human resource who can be meaningfully involved in disaster management. ${ }^{5}$

The current COVID-19 pandemic has pushed health care to the corner due to shortage of trained personnel to handle the patients affected with this infection. This has led to an enormous increase in the workload among medical health care professionals to save the lives of people, in turn resulting in burnout, increased casualties, and related issues. To address these issues, other health care professionals like dentists or oral health care professionals can contribute and can work with medical staff to reduce the impact that disaster has on lives of the people. ${ }^{6}$ In the past, dental health care professionals have contributed in various levels of disaster response systems such as triage services, sampling and immunization, providing Basic Life Support at disaster sites, primary health care, medicine distribution, and forensic assistance, as well as many more. ${ }^{6-8}$ India has currently 2.7 hundred-thousand plus registered dentists. Further, nearly 2,7000 graduates and 7,200 post-graduates are being added annually from 313 dental colleges, which shows that this huge health human resource remains available and has been under-utilized. The Indian Association of Public Health Dentistry (IAPHD; Visakhapatnam, Andhra Pradesh, India), the largest professional body of dental public health experts, demonstrate and align with public's unmet health needs and counter challenges by communicating and collaborating with appropriate stakeholders like National Institute of Disaster Management (NIDM; Rohini, Delhi, India) to advocate for changes in public health policies including disaster management. The NIDM is premier Institute of Excellence for training and research on disaster risk mitigation and management in India.

Hence towards increasing the scope of dental professionals during disaster, a nationallevel webinar was jointly organized by Maulana Azad Institute of Dental Sciences, New Delhi, IAPHD, and NIDM, as well as the Ministry of Home Affairs, Government of India, New Delhi on December 3, 2020 on the theme "Integration of Dental Health Care Professionals into Disaster Management." A group of national and internationally acclaimed faculty, researchers, and policy implementers delivered a series of erudite scientific talks along with detailed panel discussion involving various stakeholders. The technical experts discussed various strategies by which disaster management efforts can be strengthened by renewed emphasis on a multi-disciplinary and multi-sectoral approach, which will ultimately contribute to nation building.

doi:10.1017/S1049023X22000152

(C) The Author(s), 2022. Published by Cambridge University Press on behalf of the World Association for Disaster and Emergency Medicine. 
The following Call for Commitment to Action by the IAPHD, NIDM, and other important stakeholders like Ministry of Health and Family Welfare Government of India and Dental Council of India, New Delhi emerged from the deliberations at the "First National Webinar on Integration of Dental Professionals in Disaster Management" held on December 3, 2020:

\section{Standardizing Competencies and Standard Operating} Procedures (SOPs): The best practices, competencies, and SOPs for involving dental health professionals in disaster response have to be identified.

2. Capacity Building: Dental faculty will be trained in competencies and SOPs. First phase would be Training of Trainers programs, followed by transfer of knowledge and skills to other dental care professionals and students in their region.

3. Curriculum Changes: Specific competencies pertaining to disaster management will be incorporated in undergraduate dental curriculum. This will enable dental professionals to be involved in disaster response and mitigation.

4. Institutional Preparedness: All dental institutions should be disaster preparedness ready, to aid and respond to disasters at local, state, and national levels.

5. Research: Lacunae in research in disaster management should be identified and activities addressing them should be undertaken to enhance the scope of dental professionals.
6. Periodic Upgradation: Dental professionals trained in disaster management should periodically upgrade their knowledge and skills to play an effective role in disaster response and preparedness.

7. Policy Changes: Effective and meaningful integration of dental health professionals into disaster management calls for relevant policy changes at national, regional, and local levels.

This coordinated multi-sectorial approach would prepare and utilize the untapped dental health care workforce for disaster management in India. ${ }^{9}$ This declaration has definite policy implications regarding capacity building, strengthening institutional preparedness, and building a robust integrated curriculum in disaster management in India.

When disaster strikes, it becomes critical for health care providers to be ready at all times. Although first responders are primarily considered in the event of a crisis, dentists can provide critical support in medical surge situations if called upon. The function of dentists in disaster management is not defined by any clear lines. Dentists, along with other health professionals, can serve as first responders who are well-prepared to assist in the aftermath of numerous natural and man-made disasters. Thus, in a developing country like India where disasters might strike at any time, there is a need to tap into the services of a diverse group of dental specialists.

\section{References}

1. Noji EK. Public health issues in disasters. Crit Care Med. 2005;33(1 Suppl):S29-33.

2. O'Neill PA. The ABCs of disaster response. Scand J Surg. 2005;94(4):259-266.

3. Colvard MD, Lampiris LN, Cordell GA, et al. The dental emergency responder: expanding the scope of dental practice. J Am Dent Assoc. 2006;137(4):468-473.

4. More FG, Phelan J, Boylan R, et al. Predoctoral dental school curriculum for catastrophe preparedness. J Dent Educ. 2004;68(8):851-858.

5. Psoter WJ, Herman NG, More FG, et al. Proposed educational objectives for hospitalbased dentists during catastrophic events and disaster response. J Dent Educ. 2006;70(8):835-843.
6. Rekow ED. The dental team: a ready reserve or an overlooked resource? J Am Dent Assoc 2006;137(4):432-434.

7. Psoter WJ, Park PJ, Boylan RJ, Morse DE, Glotzer DL. National emergency response programs for dental health care professionals. J Am Dent Assoc. 2008;139(8):1067-1073.

8. Guay AH. The role dentists can play in mass casualty and disaster events. Dent Clin North Am. 2007;51(4):767-778.

9. Rajesh G, Binnal A, H. Pai MB, Nayak SV, Shenoy R, Rao A. Insights into disaster management scenario among various health-care students in India: a multi-institutional, multi-professional study. Indian J Community Med. 2020;45(2):220-224. 